\title{
Aloe Vera's Effect on Acetyl Cholinesterase(AChE) and Ultra Structure of Motoneurons in Synaptic Zone After Spinal Cord Injury in Rats
}

\author{
Marjan Heshmati ${ }^{*}$, Mohammad Reza Jalali², \\ Nadoushan $^{3}$ and Maryam Sharayeli ${ }^{3}$ \\ ${ }^{1}$ Department of Anatomical Sciences and Patholog ,Faculty of Medicine, Shahed University , \\ Opposite Holy Shrine of Imam Khomeini Khalij Fars Expressway Tehran, Iran. \\ ${ }^{2}$ Mostafa Khomeyni Hospital,Faculty of Medicine,Shahed University,Tehran,Iran. \\ ${ }^{3}$ Department of Anatomical Sciences and Patholog ,Faculty of Medicine ,Shahed University, \\ Opposite Holy Shrine of Imam Khomeini Khalij Fars Expressway Tehran, Iran. \\ http://dx.doi.org/10.13005/bbra/2119
}

(Received: 02 February 2016; accepted: 04 April 2016)

\begin{abstract}
Spinal cord injury(SCI) followed by transection, contusion or compression are considered to be similar to human SCI.Nowadays researchers demonstrated alternative therapies as pharmacological properties or herbs to repaire these damage.Aloe Vera is known as a plant with multi potential activity.We used this plant after SCI by Clips Aneurysm(30g/1 min). 32 female Sprague Dawley rats were divided randomly into four groups.Group 1: Sham( laminectomy) + gavage Distilled water, group2: Sham + gavage Aloe Vera gel powder $(200 \mathrm{mg} / \mathrm{kg} / \mathrm{d})$, group3: group $2+\mathrm{SCI}$, and group4:group $1+\mathrm{SCI}$ $(\mathrm{N}=8)$.After 4 weeks they were sacrificed.Morphometric study and Acetyl cholinesterase(AChE) immune staining were done.Synaptic changes was analyzed in a blinded manner for qualitative ultra structural changes.The data analyzes with Tukey's test and one-way ANOVA in SPSS21 software and P $\leq 0.05$ was considered as significant level.Decreasing motoneurons, reducing AChE immune activity with ultrastructure changes in mitochondria and synaptic zone were seen due to SCI.Usage of Aloe Vera gel powder demonstrated a reduction in death of motoneuron(Pd"0.05) with increasing AChE immunoreactivity after SCI(Pd"0.05).This herb affected on ultrastructure as seen pathological synaptic changes and mitochondria decreases.Aloe Vera gel powder effects might be due to it's antioxidant which has reduced neuronal cell death and preserved damaged neurons as intact neurons.
\end{abstract}

Key words: Aloe Vera, Spinal Cord Injury, Synapse, Rat.

Spinal Cord Injury (SCI) causes complex patterns of secondary destructive biochemical and pathophysiological processes that result in extensive tissue damage and often permanent loss of function ${ }^{1}$. Various procedures have been reported to reduce the effects of this process. SCI is one of the critical and devastating injuries

\footnotetext{
* To whom all correspondence should be addressed. Tel.: +98 21 88964792; Fax: +9821 88966310; E-mail: heshmatimarjan@hotmail.com heshmati@shahed.ac.ir
}

and causes disability and dysfunction ${ }^{2}$.As one of the gravest diseases affecting central nervous system (CNS)and ranked among the most costly disorders, because those who suffer from these disorders are affected not only with the sensory motor difficulties arising from the lesion proper, but are faced in their lifetime with numerous debilitating syndromes as well ${ }^{3}$. Nowadays achievements in neurobiology and mechanisms involving in the neuroregeneration with the idea that using chemical drugs and natural compounds of herbal origin with neurotherapeutic 
properties.So far various procedures have been reported by the researches to treat the secondary spinal cord lesions ${ }^{4}$.Further to clinical studies,pharmaceutical and non-pharmaceutical methods are note worthy. As a result of the increasing statistical frequency of the accidents, the workers have come up with the idea of presenting practical therapeutic patterns for those suffering from these lesions whose ultimate objective is to find an applied , simple and inexpensive pattern for materialization of this goal $^{5-}$ ${ }^{6}$. Along with new achievements involving in the neuroregeneration phenomen on based on biological models of spinal cord lesions, the researchers have come up with the idea that using chemical drugs and natural compounds of herbal origin with neurotherapeutic properties could be a break through to new research avenues. Given the new advancement in the recent years ${ }^{7}$. The transmission of nerve impulse at synapses is by chemical or electrical. In the chemical mechanisms the transmission takes place by means of neurotransmitters which induce the transmission of impulse from a neuron to the next. Several neurotransmitters have been identified among which acetylcholine, norepinephine, dopamine, glycine, serotonin, GABA, enkephalin, substance $\mathrm{P}$ and acid glutamic are note worthy ${ }^{8}$. Acetylcholine is one of the most important neurotransmitter ,it is transported by acetylcholine vesicle into the synaptic cleft.

Acetylcholine deficiency can cause any of these symptoms:

Alzheimerõs disease ,Anxiety, Arthritis, Autism, Multiple Sclerosis ,Involuntary movement... it is synthesized from acetyl coenzyme A and choline by acetylcholine transferase. Once discharged into the synaptic cleft and binding to the ACh receptors on the post-synaptic membrane, relaying the signal from the nerve. Acetyl cholinesterase(AChE), is localised in cholinergic cell bodies and axons it is synthesized in presynaptic neuron and stored in the axons. Myelinated axons contain less acetylcholine esterase. It is worth mentioning that acetylcholine esterase affects the growth of the axon ${ }^{9}$.It is anchored in presynaptic membranes of the cholinergic neuron. Also, it is found in postsynaptic membranes and in the synaptic cleft ${ }^{10}$. However, the occurrence of AChE in non-cholinergic cells has been frequently reported ${ }^{11-13}$.AChE, terminates the signal transmission by hydrolyzing ACh. The liberated choline is taken up again by the presynaptic nerve and ACh is synthetized by combining with acetyl-CoA through the action of choline acetyltransferase(ChAT). Relevant receptor, it is broken to acetate and choline by the AChE. AChE is found at mainly neuromuscular junctions and cholinergic brain synapses, where its activity serves to terminate synaptic transmission. It belongs to carboxylesterase family of enzymes. It is the primary target of the nerve agent $\operatorname{sarin}^{14}$. In the study made by Manolov and Davidoff AChE was introduced as a marker to investigate the mode of action of cholinergic system at the ventral ramus ${ }^{15}$. In SCI, there is a marked reduction in expression of $\mathrm{AChE}^{16}$.Study indicate following neuronal damage in midbrain the expression of AChE -receptor is increased which is due to the reduction $\mathrm{AChE}^{17}$. Cherian et al. demonstrated that in spinal cord injury, the rate of AChE is decreased whereas use of dexamethazone increases $\mathrm{it}^{16}$. One of the frequently used methods nowadays is the use of chemical or herbal drugs.Among these drugs, Prednisolone ${ }^{18}$ and Dexamethasone ${ }^{19}$ are noteworthy .The chemical or natural compounds are used to prevent the apoptosis of neurons, on the other hand to prevent the glial reaction after neuronal damage.Recently, it is supposed that the use of natural compounds with herbal origin, instead of the chemical drugs,has simplicity and more benefit . Aloe Vera, one of the acient medicinal plants recently is being study because of itõs multiple effects $^{20}$. Aloe Vera or A. barbadensis belongs to Liliaceae and has been extensively used as a medicinal plant and is usefull for wound healing ${ }^{21}$.This plant has many medicinal and curing properties and is classified among plants which work wonders ${ }^{22-23}$. In the Iranian traditional medicine it is rated as a plant with warm and dry properties and is presently used to treat a plethora of diseases like migraine, indigestion, acne, internal and external wounds ${ }^{24-25}$. In addition, it stimulates dermal fibroblasts,to promote synthesis of collagen and elastin and to increase skin elasticity ${ }^{7}$. Gelatinuous material found in aloe leaves contains $96 \%$ water whereas the balance $4 \%$ contains many compounds of which 75 types have been identified ${ }^{26}$.The compounds found in aloe gel are 
mainly polysacharides which decrease inflammatory and induces skin growth and regeneration ${ }^{27}$ responsible for regenerating mechanisms , antibacterial , antimicrobial , Anti oxidant ${ }^{28-29}$ and Anti cancer ${ }^{30}$. Furthermore, aloe gel contains a glycoprotein which prevents swelling and pain while accelerating the recovery. Anthraquinone found in aloe has efficient purgative properties $^{29}$. For demonstrate Aloe Vera effects on regeneration after nervous system injury, we damaged the neurons by the use of the method of Clips Aneurysm, which introduced by Dolan and Tator ,they proposed aneurysm clips for mechanical pressure on the spinal cord in order to damage neurons in the means of evaluate pathological effects ${ }^{31}$.

\section{MATERIALSAND METHODS}

Animals and Surgical procedure:The animal care and all experimental procedure were done according to ethical guidelines established by the Shahed University. 32 young adult female Sprague-Dawley rats weighing 200-250 g, from Razi Institute ( Karaj,Iran)were purchased. All rats were fed and kept, for a week, under the standard conditions of 12-hour light/ dark cycle, temperature of $22^{\circ}-23^{\circ} \mathrm{C}$ with free access to food (Pars Animal Feed Co. -Iran) and water. Then they were randomly devided to 4 groups: group1: Sham + gavage Distilled water, group2: Sham + gavage Aloe Vera gel powder, group3: group 2+SCI, and group4:group $1+\mathrm{SCI}(\mathrm{N}=8)$. SCI were done by Clips Aneurysm after anesthetizing the animals (ketamine $100 \mathrm{mg} / \mathrm{kg}$ / xylazine $5 \mathrm{mg} / \mathrm{kg}$, ip) and exposure of the spinal cord through laminectomy, an extradural compression was applied at T6 level $30 \mathrm{~g}$ by clips aneurysm( Cadman, Johnson and Johnson Inc/ catalog No. 20-1264). Which was done by using clip applicator for 1 minute. Incision site of muscles,fascia and skin were separately sutured with 6-0 and 3-0 suture treads. Cephazoline and 5$8 \mathrm{ml}$ Lactate serum was administered intraperitoneally if needed Animals were maintained at an ambient temperature of $25-27^{\circ} \mathrm{C}^{31}$. Manual compression of bladder was performed three times daily and all efforts were done to prevent bladder infection and any injury due to the sensory disorders. Daily administration of Aloe Vera gel powder $(200 \mathrm{mg} / \mathrm{kg} / \mathrm{d})$ or distilled water was given by gavage base on their groups for four weeks. The sham groups were only subjected to laminectomy without any compression applied on the cord. After 4 weeks (28 days)animals were sacrificed by lightly anesthetized with ketamine/ xylazinein ,cardiac perfusion was done. T9 vertebra extracted and transferred to fixative according to their protocol as: motoneuron counting and immunohistochemical technique $(\mathrm{N}=4)$, ultrastructural studies $(\mathrm{N}=4)$. Aloe Vera gel powder: Aloe gel powder was prepared by the procedure prescribed in the paper presented by Misawa et $a l .^{32}$.We used fresh leaves of Aloe Vera from a single garden plant, identification of leaves was done by herbarium of the department of Acient Medicine of Shahed University Iran. Leaves were washed by water ,the inner gel was obtained by clean sharp knife.By hot air drying the gel were powdered and suspended in distilled water as a homogenized to $50 \mathrm{mg} / \mathrm{ml}$,sterility was cheked in Microbiology department and stored in dark container at $-20^{\circ} \mathrm{C}$ for later use.

\section{Preparation samples}

For light microscope, spinal cord was removed and fixed in $10 \%$ formalin solution and the tissues were processed for paraffin embedding, by using microtome rotary(Leica 820)for 6 micrometer diameter slices. It is worth mentioning that to monitor modifications in neurons and their precise location in ventrolateral ramus, so the spinal cord sections were randomly colored by routine hematoxylin eosin technique.The serial sections were stained with Cresyl Violet $(0.1 \%)$ (Merck/Germany) for cell counting.. Motor neurons in ventrolateral ramus with nucleus larger than 10 micrometer and with one distinct nucleolus were counted.Total motoneurons of both sides of spinal cord in each relevant segment were counted according to Bao and $\mathrm{Liu}^{33}$. Immunohistochemistry technique was done for demonstrating . AChE in ventrolateral motoneuron's. Totally 20 crosssections were prepared for this step. They were labeled with , mouse anti- AChE (Chemicon International) as primary antibody and procceed by goat anti-mouse (Chemicon International) as the secondary antibody. Upon application of DAB on slice, $\mathrm{DAB}$ reacts with peroxidase in the secondary antibody and gives rise to a brownish color. As explained above, the rate and intensity of acetylcholine esterase is the main objective of this 
study and, by the same taken, this enzyme depicts the modality of rate and hydrolysis of acetylcholine as a neurotransmitter. Based on the manifestation patterns, the assay is performed as a percentage in neurons counted. For electron microscope,in means of ultrastructure study,the spinal cord tissue were perfused by Karnovsky's fixative for $24 \mathrm{~h}$. and immersed in $2.5 \%$ glutaraldehyde in phosphate buffer (0.1 M,PH 7.4) and post- fixed in 1\%osmium tetroxide in phosphate buffer.Sections were cut,stained with uranyl acetate and lead citrate and examined under Zeiss EM 900( Germany).

\section{Data analysis}

The data were tested for normality using S-K test and analysed by using Student's t-test and one-way ANOVA with software SPSS Ver 21.The significance level $(\mathrm{p} \leq 0.05)$ for motoneuron counting and $(\mathrm{P} \leq 0.05)$ for $\mathrm{AChE}$ labeling.

\section{RESULTS}

The survey of motoneurons in the ventrolatral ramus indicated that in two groups which received mechanical pressure in addition to laminectomy, the decrease in motoneurons in the ventrolateral ramus is quite visible (Fig 1).The results of the motoneurons counting at the location of the pressure was exerted, in other words, Nissl bodies are greatly destroyed and cytoplasm is clear in the perimeter of nucleus with apoptotic bodies (Fig 2).

Whereas in the groups 1 and 2 which had been subjected to no pressure, the number of motoneurons differed [2306 \pm 140 in the group 1 compared to $2451 \pm 100$ in the group 2] however it was not statistically significant. Furthermore, comparison of these two groups (1 and 2) with the other ones (3 and 4) which had received mechanical pressure with Aloe gel powder or distilled water, there was a significant difference (Table 1). The comparison results in terms of total cell count of motor neurons between the two groups 3 and 4 which had received mechanical pressure indicated that in the non-treated group, there is a significant decrease in motor neurons $(\mathrm{P}<0.05)$.In other words, in the group which had received Aloe Vera gel powder for 4 weeks, motoneurons have been preserved $(\mathrm{P}<0.05)$.

Motoneurons in antrolateral horn of spinal cord in groups (Table 1), indicate in group 2 they are more than three other groups.Group 2 was used as a reference to evaluate differences. Percentage of reduction have been calculated (Tabel 2).

Table 1. Mean and SD of motoneurons in the anterolateral horn of spinal cord

\begin{tabular}{lcc}
\hline Statistical Analysis & Mean \& SD motoneurons located in lesion area & groups \\
\hline $\mathrm{P}<0.05$ & $2306 \pm 140$ & 1: Sham + Distilled water \\
$\mathrm{P}<0.05$ & $2451 \pm 100$ & 2: Sham + Aloe Vera \\
$\mathrm{P}<0.05$ & $* 1389 \pm 137$ & 3: SCI + Aloe Vera \\
$\mathrm{P}<0.05$ & $\# * 893 \pm 108$ & 4: SCI + Distilled water \\
\hline
\end{tabular}

*Significant difference group 3 and 4 with two groups 1 and $2(\mathrm{P}<0.05)$.

\# Significant difference group 4 with other groups $(\mathrm{P}<0.05)$.

Table 2. Percentage of reduction motoneurons in antrolateral horn of spinal cord relative to group 2

\begin{tabular}{lc}
\hline Study Groups & Percentage of decrease \\
\hline Group 1 & $5.9 \%$ \\
Group 2 & 0 \\
Group 3 & $* 37 \%$ \\
Group 4 & $\# * 57 \%$ \\
\hline
\end{tabular}

*Significant difference with group 1 and $2(\mathrm{P}<0.05)$.

\# Significant difference with group 1,2 and $3(\mathrm{P}<0.05)$.
Table 3. Percentage of motor neurons responsive to immunohistochemical staining for $\mathrm{AChE}$ compared to the total motor neurons

\begin{tabular}{lcccc}
\hline & Group 1 & Group 2 & Group 3 & Group 4 \\
\hline $\begin{array}{l}\text { Acetylcholine } \\
\text { esterase }\end{array}$ & $85 \%$ & $88 \%$ & $* 36 \%$ & $* \# 21 \%$ \\
\hline
\end{tabular}

*Significant difference with group 1 and $2(\mathrm{P}<0.05)$ \#Significant difference group 4 with other groups $(\mathrm{P}<$ $0.05)$. 
Results of Light Microscopy (Immunohistochemistry)

The effect of Aloe Vera gel powder on expression of AChE was assessed by immunohistochemical technique.To this end, the rate of it, was evaluated. By using this technique, the final reaction product of AChE was visualized as a brownish precipitate in the perikaryon of the neuron.By this procedure, those motor neurons in ventrolateral ramus which were positive in terms of AChE reaction were counted (Fig. 3) then the

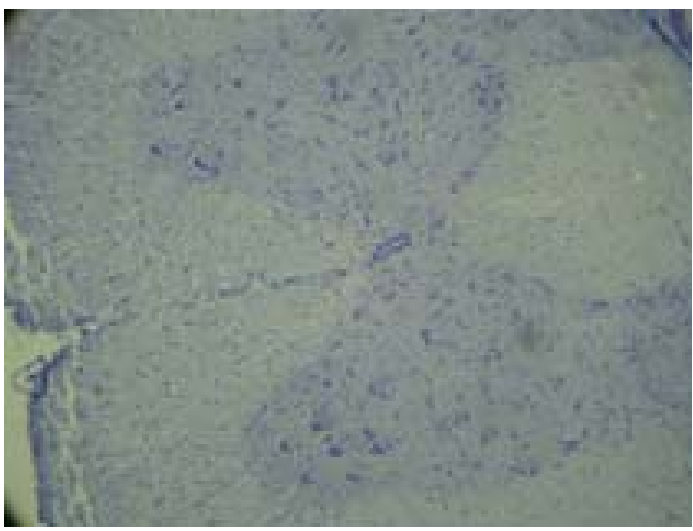

Fig. 1. Cross section of spinal cord tissue in rat ,Cresyl Violet staining. Gray and white matter are seen after mechanical pressure application,decline in number of motoneuron are visible (X 40)

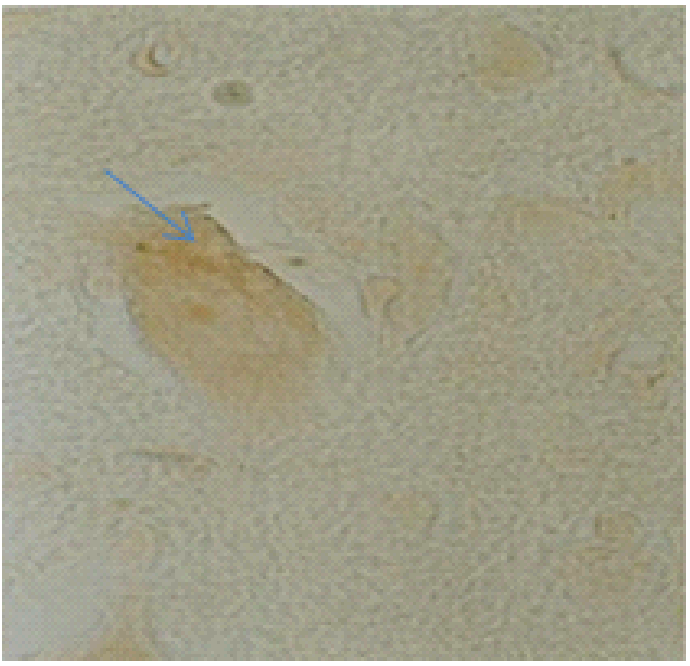

Fig. 3. Arrow indicated a motoneuron by immunohistochemical staining for AChE in Group 1 (X 100) percentage of positive neurons calculated (Table 3).

\section{Result of Electron Microscopy (ultrastructure study)}

Induce of SCI synaptic changes were visible, reduction of electron density in active zone with irregularity in pre and post synaptic membrane ,collapsed synaptic cleft with low electron density in the synaptic active zone. Dispressed synaptic vesicle with mitochondria swollen from moderately to severely with

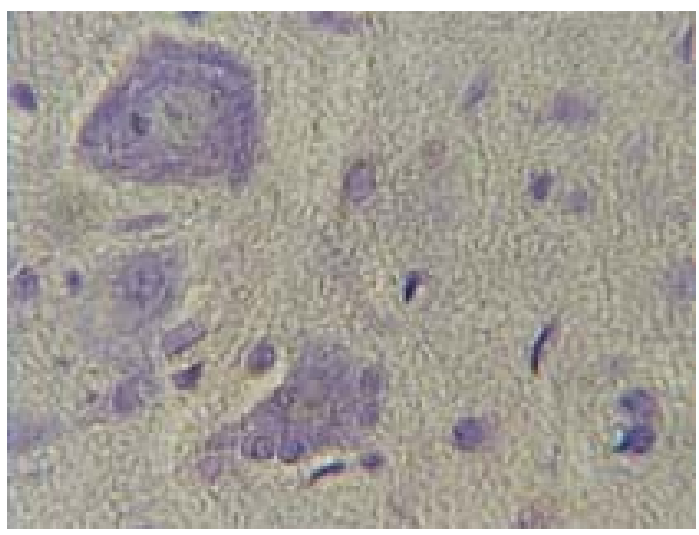

Fig. 2. Cresyl Violet staining.Chromatolysis of motoneuron with apoptotic bodies are visible (X 100)

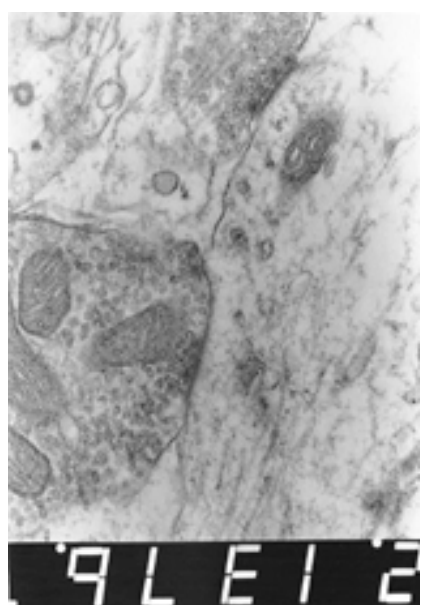

Fig. 4. An electron micrograph of synapse in a motoneuron from the spinal cord after SCI. which shows displacement of the synaptic vesicles ,collapsed synaptic cleft with low electron density in the synaptic active zone (X 35000) 
irregularity in outer and inner membrane and poorly defined cristae(Fig 4).Increased mitochondria matrix density with some vesiculated body in it(Fig 5). These changes are most visible in group 4 which has received compression with out any treatment.Induce of Aloe Vera gel in group 3 these changes reduced visibly.

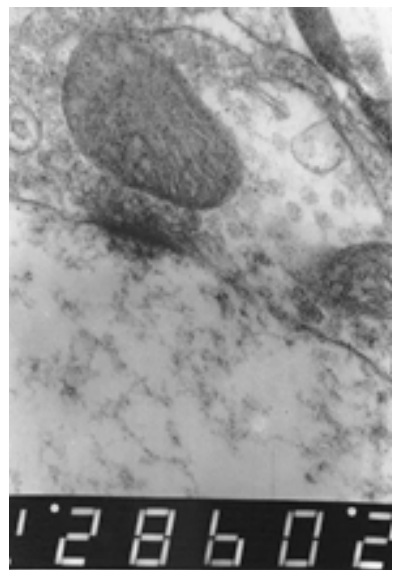

Fig. 5. An electron micrograph of synapse in a motoneuron from the spinal cord after SCI which shows irregularity in pre and post synaptic membrane,with mitochondria vesiculated and swelling,with poorly defined cristae and larger than normal (X 50000)

\section{DISCUSSION}

We used SCI as described earlier by Krishna et al., in animal model training ${ }^{34}$.Results in this study showed motoneuron reduced after SCI , which is consistent with the findings of other investigators who reported SCI causes motoneuron death (4, 5 and 16).After SCI apotosis took place and reported it begin after 6 hours and continue to 3 weeks $^{35}$ in another study reported it reaches maximum second or even third day after injury ${ }^{36}$. Cherian et al. reported a decrease in phospholipid rate within the first 24 hours following the spinal cord lesion as well as a decrease in acetylcholine esterase within one week following it in adult rats ${ }^{16}$. In our study comparing third with fourth group, in group fourth motoneuron loss are significant. Group first and second which were as groups with no having any pressure,total cell count was as the same as with no statistically significant. It means in group second which received Aloe Vera gel powder ,motoneuron were as intact group (first group)which did not received this herb,it seems
Aloe Vera gel powder has not any significant effect on motoneuron cell number.The number of motoneuron in third group which received Aloe Vera gel powder in compare to fourth indicate the probably effect of Aole Vera gel powder as a preservative herb.Nowa days many researchers published the hypothesis and protocol as a cascade events after SCI, such as: free radical formation ${ }^{37}$.Peroxynitrite,membrane lipids and protein cell homeostasis changes ${ }^{38}$. Synaptic stripping or synaptic contact losses ${ }^{39}$. Neurotransmitter transferring deficiency ${ }^{40}$. Astrocyte activation and inflammatory signaling ${ }^{41}$. However, following SCI plasticity change is considered as the most important event following neuronal injury ${ }^{42-43}$. A cascade of event accure after SCI and one of the most important seems accure in synaptic zone and nerve counduction.In neural pathway neurotransmitter releases in synaptic cleft and it act on post synaptic membrane for neuron surviving,any changes in this proccess causes neuron apoptosis ${ }^{4-45}$. As table 2 shows in third group inspite of spinal cord pressure more than 2/ 3 neuron has been preserved but in fourth group the vital neuron decreased and this deduction is more than $1 / 2$ neurons. This herb seems has an un known potential to maintain motoneuron after SCI . Zhang and Tang reported Huperzine A (HupA), a novel alkaloid isolated from a Chinese herb has multi functional effect, include modification of betaamyloid peptide processing, reduction of oxidative stress, neuronal protection against apoptosis, neuroprotective effects that go beyond the inhibition of AChE , regulation of the expression and secretion of nerve growth factor (NGF) and NGF signaling ${ }^{46}$. In our study after four weeks, the efficiency of this herb seems similar as preserving neurons and immunohistochemistry results for AChE demonstrates this effect .On the other hand comparing it's expression in group first and second indicates that Aloe Vera gel powder has not any significant effect. So it means aloe vera has a potencial efficiency which switch on after neuron damaged but not in normal coundition. As mentioned in table 3 after SCI ,AChE expression decreses as the same as reported earlier by Romeo demonstrated acetylcholine esterase receptor decreased ${ }^{17}$, Nacimento et al., reported a transient reduction in expression of acetylcholine esterase was observed in the ventral ramus in adult rats 
following spinal cord lesions ${ }^{47}$.The results of Mis et al. which demonstrated localization of, cells expressing AChE mRNA in rat spinal cord ${ }^{48}$ are in keeping with those achieved by Manolov and Davidoff., demonstrated AChE -activity was observed on the cellular membrane, cytoplasm of the perikarya, proximal processes of the motoneurons ${ }^{15}$, Nacimento et al., ${ }^{47}$ and Romeo et al., ${ }^{17}$, demonstrated decreasing AChE following spinal cord injuried.This has raised the theory that decreasing the enzymatic expression could be served as a criterion to survey cholinergic system in ventral ramus ${ }^{15,47,48}$. In our study indicated Aloe Vera has significant effect on its expression. As it is showed in table 3 in third group it is expressed in more than $1 / 3$ of neurons.But in fourth group this expression decreased significantly and it is not seen in $80 \%$ of vital neurons. This is the maximum in both group 1 and 2 which is responsible for keeping morphometric results, whereas that in group 4 is the minimum which reflects the decrease in motor neurons number. Comparing groups 3 and 4 where the enzymatic expression was significantly different, one could assert that Aloe Vera gel powder increases the expression rate and, put in other words, preserve the neurons. As mentioned ultra structural changes in this study has accurred.These changes are: reduction of electron density in active zone, irregularity in pre and post synaptic membrane, collapsed synaptic cleft, low electron density in the synaptic active zone. Dispressed synaptic vesicle, mitochondria swollen with increasing matrix density, irregularity in outer and inner membrane with poorly defined cristae with some vesiculated body in it (Fig 4 and 5).As other reported synaptic structure beside homeostasis of extra cellular matrix are the most important factor for cell survival ${ }^{49-50}$. In addition to mention cholinergic system, the presence of AChE in the cholinergic nervous system has neuroprotective properties due to two essential mechanisms, the extent that is said enzyme prevents the excessive stimulation of postsynaptic neuron , to boot, activates the ATP-mediated K channels which is endowed with neuroprotective effect however, the high rated of acetylcholine enzyme in the long run ends up with neurotoxicity as in $\mathrm{ALS}^{51}$. It is established mitochondria play an important role in intrinsic apoptotic pathway ${ }^{52}$ by cell homeostasis maintaining ${ }^{53}$, regulating signaling pathways ${ }^{54}$ by cell signaling ${ }^{55}$. Interesting finding in this study is mitochondria swelling with changes in it's structure as an important organel in apoptosis ${ }^{56-57}$. At least ultra structure changes after SCI belongs to group 2 as compare with fourth group. This seems pararel with AChE expression as a factor for maintaining motoneurons.Many investigators show, it has effect on intracellular events that leads to death or maintaining cells ${ }^{58,59-60}$. On the whole results show, Aloe Vera may be has significant effect on neuron maintaining or preserving from death .Some other researcher show multi potential effect of this herb as indicated, anti inflammatory in human colorectal mucosa,changing gastric microcirculatory and cytokine levels ,causing down regulating interlukin 6 and 8 , dis attachment leukocytes, increasing level of interlukin 10,reduction TNF $\alpha$ and on the whole reduction inflammatory process achive ${ }^{61-62}$. Protective effect of Aloe Vera on mild damage caused by type-II diabetes on kidney tissue ${ }^{63}$. On the other hand Boudreau reported Aloe vera products contain toxicological activities as:diarrhea, electrolyte imbalance, kidney dysfunction ${ }^{64}$.Nowadays anti oxidatnt potentiality of Aloe Vera is reported by Ozsoy which this effect could be related to the presence of phenolic compounds and antioxidant vitamins .Inhibiting peroxidation of liposomes and reduction malondialdehyde levels upon cellular pathways, it indicate Aloe Vera extract may useful for treating degenerative disorders ${ }^{65}$. Other reported prooxidant action of polyphenolics in Aloe emodinis is more than antioxidant activity,it seems is important mechanism for their anti cancer and apoptosis abilities ${ }^{66}$.Gupta reported Aloe Vera has multi activity such as inhibition histamine releasing,anti-inflammatory,anti viral,anti microbial,anti cancer and anti oxidant is depend on Barbaloin ${ }^{67}$ which is in Aloe vera leaves ${ }^{26}$. In other word Aloe Vera causes bone growth and tibia length with body mass increasing in rat as a growth factor $^{59}$. On contrast Misawa reported it decreased body mass ${ }^{32}$. Friedman and Si demonstrated Aloe Vera affect in crayfish neuro muscular junction is as increasing nerve stimulation amplitude and change neuro transmission process which suggested analgesis and anti inflammatory effects $^{68}$.Lu et al. reported following cerebral ischemia Aloe Vera had a protective effect, that 
may be due to the inhibition of neuronal cell apoptosis ${ }^{69}$.By these finding and theories it seems Aloe Vera has some different effect as it is known multi potential herb and as an anti oxidant can be supposed make this herb act as a neuroprotective herb for maintaining motoneurons and their structure in SCI.

\section{CONCLUSION}

On the whole in this study ,seems Aloe Vera plant has neuroprotective properties which causes the neurons to be preserved.

\section{REFERENCES}

1. Rabchevsky, A.G., Patel, S.P., Springer, J.E. Pharmacological interventions for spinal cord injury: where do we stand? How might we step forward? Pharmacol Ther. 2011 Oct;132(1):1529. doi: 10.1016/j.pharmthera.2011.05.001. Epub 2011 May 14. Review.

2. Chen, K., Deng, S., Lu, H., Zheng, Y., Yang, G., Kim, D., Cao, Q., Wu, J.Q. RNA-seq characterization of spinal cord injury transcriptome in acute/subacute phases: a resource for understanding the pathology at the systems level. PLoS One. 2013 Aug 9;8(8):e72567. doi: 10.1371/journal.pone. 0072567. eCollection 2013.

3. Frontera, W.R., Grimby, G., Basford, J., Müller, D., Ring, H. Publishing in physical and rehabilitation medicine. J Rehabil Med. 2008 Mar;40(3):161-5. doi: 10.2340/16501977-0171.

4. Hulsebosch, C.E. Recent advances in pathophysiology and treatment of spinal cord injury.Adv Physiol Educ.2002:26(1-4):238-55.

5. Crowe, M.J., Bresnahan, J.C., Shuman, S.L., Masters, J.N., Beattie, M.S. Apoptosis and delayed degeneration after spinal cord injury in rats and monkeys.Nat Med. 1997 Jan;3(1):736.

6. Conti, A., Cardali, S., Genovese, T., Di Paola, R., La Rosa, G.J. Role of inflammation in the secondary injury following experimental spinal cord trauma. Neurosurg Sci. 2003 Jun;47(2):8994.

7. Muller, M.J., Hollyoak, M.A., Moaveni, Z., Brown, T.L., Herndon, D.N., Heggers, J.P. Retardation of wound healing by silver sulfadiazine is reversed by Aloe vera and nystatin. Burns. 2003 Dec;29(8):834-6.

8. Andreae, L.C., Burrone, J. The role of neuronal activity and transmitter release on synapse formation. Curr Opin Neurobiol. 2014 Mar 12 ;27C:47-52. doi: 10.1016/j.conb.2014.02.008. [Epub ahead of print]

9. Wevers, A. Localisation of pre- and postsynaptic cholinergic markers in the human brain. Behav Brain Res. 2011 Aug 10;221(2):341-55. doi: 10.1016/j.bbr.2010.02.025. Epub 2010 Feb 16. Review.

10. Abreu-Villaça, Y., Filgueiras, C.C., Manhães, A.C. Developmental aspects of the cholinergic system. Behav Brain Res. Epub 2010 Jan 6,10;221(2):367-78. doi: 10.1016/ j.bbr.2009.12.049. Review.

11. McIntosh, J.M., Absalom, N., Chebib, M., Elgoyhen, A.B., Vincler, M. Alpha9 nicotinic acetylcholine receptors and the treatment of pain. Biochem Pharmacol. 2009 Oct 1;78(7):693702. doi: 10.1016/j.bcp.2009.05.020. Epub 2009 May 27.

12. Greenfield, S. Discovering and targeting the basic mechanism of neurodegeneration: the role of peptides from the C-terminus of acetylcholinesterase: non-hydrolytic effects of ache: the actions of peptides derived from the C-terminal and their relevance to neurodegeneration. Chem Biol Interact. 2013 May 25;203(3):543-6. doi: 10.1016/ j.cbi.2013.03.015. Epub 2013 Apr 3.

13. Bahrami, F., Yousefpour, M., Mehrani, H., Golmanesh, L., Sadraee, S.H., Khoshbaten, A., Asgari, A. Type of cell death and the role of acetylcholinesterase activity in neurotoxicity induced by paraoxon in cultured rat hippocampal neurons. Acta Biol Hung. 2009 Mar;60(1):1-13. doi: 10.1556/ABiol.60.2009.1.1.

14. Phillis, J.W. Acetylcholine release from the central nervous system: a 50-year retrospective. Crit Rev Neurobiol. 2005;17(3-4):161-217.

15. Manolov, S., Davidoff, M. Acetylcholinesterase activity, choline acetyltransferase and GABA immunoreactivity in the ventral horn of the spinal cord of rats during chromatolysis]. Rev Neurol (Paris). 1989;145(1):55-9. [Article in French]

16. Cherian, L., Kuruvilla, A., Chandy, M.J., Abraham, J. Changes in phospholipids and acetylcholinesterase during early phase of injury to spinal cord-an experimental study in rats. Indian J Physiol Pharmacol. 1996 Apr;40(2):134-8.

17. Romeo, C., Raveendran, A.T., Sobha, N.M., Paulose, C.S. Cholinergic receptor alterations in the brain stem of spinal cord injured rats. Neurochem Res. 2013 Feb;38(2):389-97. doi: 10.1007/s11064-012-0931-x. Epub 2012 Nov 27 
18. Cate, H.S., Wu, Q,Z., Kemper, D., Merlo, D., Wang, H.X., Fang, K., Egan, G.F., Kilpatrick, T.J. Influence of methylprednisolone on magnetic resonance and histological measures during cuprizone-induced demyelination. Neurosci Lett. 2010 Oct 8;483(1):47-52. doi: 10.1016/j.neulet.2010.07.060. Epub $2010 \mathrm{Jul}$ 30.

19. Mohammadi, R., Azad-Tirgan, M., Amini, K. Dexamethasone topically accelerates peripheral nerve repair and target organ reinnervation: a transected sciatic nerve model in rat. Injury. 2013 Apr;44(4):565-9. doi: 10.1016/ j.injury.2012.10.013. Epub 2012 Nov 3.

20. Lee, K.H., Kim, J.H., Lim, D.S., Kim, C.H. Antileukaemic and anti-mutagenic effects of di(2ethylhexyl)phthalate isolated from Aloe vera Linne. J Pharm Pharmacol. 2000 May;52(5):5938.

21. Khan, A.W., Kotta, S., Ansari, S.H., Sharma, R.K., Kumar, A., Ali, J.Formulation development, optimization and evaluation of aloe vera gel for wound healing .Pharmacogn Mag. 2013 Oct-Dec; 9(Suppl 1): S6-S10.

22. Bahramsoltani, R., Farzaei, M.H., Rahimi, R. Medicinal plants and their natural components as future drugs for the treatment of burn wounds: an integrative review. Arch Dermatol Res. 2014 Jun 4. [Epub ahead of print].

23. Boonyagul, S., Banlunara, W., Sangvanich, P., Thunyakitpisal, P. Effect of acemannan, an extracted polysaccharide from Aloe vera, on BMSCs proliferation, differentiation, extracellular matrix synthesis, mineralization, and bone formation in a tooth extraction model. Odontology. 2013 Jan 12. [Epub ahead of print]

24. Hajhashemi, V., Ghannadi, A., Heidari, A.H. Anti-inflammatory and wound healing activities of Aloe littoralis in rats. Res Pharm Sci. 2012 Apr;7(2):73-8.

25. Khedmat, H., Karbasi, A., Amini, M., Aghaei, A., Taheri, S. Aloe vera in treatment of refractory irritable bowel syndrome: Trial on Iranian patients. J Res Med Sci. 2013 Aug;18(8):732. No abstract available.

26. Patel, D., Patel, K., Tahilyani, V. Barbaloin: A concise report of its pharmacological and analytical aspects. Asian Pac J Trop Biomed. 2012 Oct;2(10):835-8. doi: 10.1016/S22211691(12)60239-1.

27. Sierra-García, G.D., Castro-Ríos, R., GonzálezHorta, A., Lara-Arias, J., Chávez-Montes, A. Acemannan, an extracted polysaccharide from Aloe vera: A literature review. Nat Prod Commun. 2014 Aug;9(8):1217-21. Review.

28. Rajasekaran, S., Sivagnanam, K., Subramanian,
S. Antioxidant effect of Aloe vera gel extract in streptozotocin-induced diabetes in rats. Pharmacol Rep. 2005 Jan-Feb;57(1):90-6.

29. El-Shemy, H.A., Aboul-Soud, M.A., NassrAllah, A.A., Aboul-Enein, K.M., Kabash, A., Yagi, A. Antitumor properties and modulation of antioxidant enzymes' activity by Aloe vera leaf active principles isolated via supercritical carbon dioxide extraction. Pharm Pharmacol. 2000 May;52(5):593-8.

30. Pan, Q., Pan, H., Lou, H., Xu, Y., Tian, L. Inhibition of the angiogenesis and growth of Aloin in human colorectal cancer in vitro and in vivo. Cancer Cell Int. 2013 Jul 12;13(1):69. doi: 10.1186/1475-2867-13-69.

31. Dolan, E.J., Tator, C.H. A new method for testing the force of clips for aneurysms or experimental spinal cord compression. J Neurosurg. 1979 Aug;51(2):229-33.

32. Misawa, E., Tanaka, M., Nabeshima, K., Nomaguchi, K., Yamada, M., Toida ,T., Iwatsuki , K. Administration of dried Aloe vera gel powder reduced body fat mass in diet-induced obesity (DIO) rats. J Nutr Sci Vitaminol (Tokyo). 2012;58(3):195-201.

33. Bao, F., Liu, D. Peroxynitrite generated in the rat spinal cord induces neuron death and neurological deficits. Neuroscience. 2002;115(3):839-49.

34. Krishna, V., Andrews, H., Jin, X., Yu, J., Varma, A., Wen, X., Kindy, M. A contusion model of severe spinal cord injury in rats. J Vis Exp. 2013 Aug 17;(78). doi: 10.3791/50111.

35. Hubli, M., Dietz, V. The physiological basis of neurorehabilitation-locomotor training after spinal cord injury. J Neuroeng Rehabil. 2013 Jan 21;10:5. doi: 10.1186/1743-0003-10-5

36. Rong, W., Wang, J., Liu, X., Jiang, L., Wei, F., Hu, X., Han, X., Liu, Z. Naringin treatment improves functional recovery by increasing BDNF and VEGF expression, inhibiting neuronal apoptosis after spinal cord injury. Neurochem Res. 2012 Aug;37(8):1615-23. doi: 10.1007/ s11064-012-0756-7. Epub 2012 Mar 28.

37. Vaziri, N.D., Lee, Y.S., Lin, C.Y., Lin, V.W., Sindhu, R.K. NAD(P)H oxidase, superoxide dismutase, catalase, glutathione peroxidase and nitric oxide synthase expression in subacute spinal cord injury. Brain Res. 2004 Jan 2;995(1):76-83.

38. Bains, M., Hall, E.D. Antioxidant therapies in traumatic brain and spinal cord injury. Biochim Biophys Acta. 2012 May;1822(5):675-84. doi: 10.1016/j.bbadis.2011.10.017. Epub 2011 Nov 4. Review.

39. Alvarez, F.J., Fyffe, R.E., Dewey, D.E., Haftel, 
V.K., Cope, T.C. Factors regulating AMPA-type glutamate receptor subunit changes induced by sciatic nerve injury in rats. J Comp Neurol.. 2000 Oct 16;426(2):229-42.

40. Yi, J.H., Hoover, R., McIntosh, T.K., Hazell, A.S. Early, transient increase in complexin I and complexin II in the cerebral cortex following traumatic brain injury is attenuated by $\mathrm{N}$ acetylcysteine. J Neurotrauma. 2006 Jan;23(1):86-96.

41. Nicaise, C., Frank, D.M., Hala, T.J., Authelet, M., Pochet, R., Adriaens, D., Brion, J.P., Wright ,M.C., Lepore, A.C. Early phrenic motor neuron loss and transient respiratory abnormalities after unilateral cervical spinal cord contusion. J Neurotrauma. 2013 Jun 15;30(12):1092-9. doi: 10.1089/neu.2012.2728.

42. Palkovits, M. Neuropeptide messenger plasticity in the CNS neurons following axotomy. Mol Neurobiol. 1995 Apr-Jun;10(2-3):91-103.

43. Miller, G.W., Erickson, J.D., Perez, J.T., Penland, S.N., Mash, D.C., Rye ,D.B., Levey, A.I. Immunochemical analysis of vesicular monoamine transporter (VMAT2) protein in Parkinson's disease. Exp Neurol. 1999 Mar;156(1):138-48.

44. Freire, M.A. Pathophysiology of neurodegeneration following traumatic brain injury. West Indian Med J. 2012 Oct;61(7):7515.

45. Funa, K., Sasahara, M. The roles of PDGF in development and during neurogenesis in the normal and diseased nervous system. J Neuroimmune Pharmacol. 2014 Mar;9(2):16881. doi: 10.1007/s11481-013-9479-z. Epub 2013 Jun 15.

46. Zhang, H.Y., Tang, X.C. Neuroprotective effects of huperzine A: new therapeutic targets for neurodegenerative disease. Trends Pharmacol Sci. 2006 Dec;27(12):619-25. Epub 2006 Oct 23.

47. Nacimiento, W., Schlözer, B., Brook, G.A., Tóth, L., Töpper, R., Noth, J., Kreutzberg, G.W. Transient decrease of acetylcholinesterase in ventral horn neurons caudal to a low thoracic spinal cord hemisection in the adult rat. Brain Res. 1996 Apr 1;714(1-2):177-84.

48. Mis, K., Mars, T., Jevsek, M., Brank, M., ZajcKreft, K., Grubic, Z. Localization of mRNAs encoding acetylcholinesterase and butyrylcholinesterase in the rat spinal cord by nonradioactive in situ hybridization. J Histochem Cytochem. 2003 Dec;51(12):1633-44.

49. Gerst, J.E. SNAREs and SNARE regulators in membrane fusion and exocytosis. Cell Mol Life Sci. 1999 May;55(5):707-34.
50. Benarroch, E.E. Synaptic vesicle exocytosis: molecular mechanisms and clinical implications. Neurology. 2013 May 21;80(21):1981-8. doi: 10.1212/WNL.0b013e318293e3cd.

51. Rodríguez-Ithurralde, D., Olivera, S., Vincent, O., Maruri, A. In vivo and in vitro studies of glycine- and glutamate-evoked acetylcholinesterase release from spinal motor neurones: implications for amyotrophic lateral sclerosis/motor neurone disease pathogenesis. J Neurol Sci. 1997 Oct;152 Suppl 1:S54-61.

52. Iverson, S.L., Orrenius, S. The cardiolipincytochrome c interaction and the mitochondrial regulation of apoptosis. Arch Biochem Biophys. 2004 Mar 1;423(1):37-46.

53. Green, D.R., Reed, J.C. Mitochondria and apoptosis. Science. 1998 Aug 28;281(5381):1309-12.

54. Bienertova-Vasku, J., Sana, J., Slaby, O. The role of microRNAs in mitochondria in cancer.Cancer Lett. 2013 Aug 9;336(1):1-7. doi: 10.1016/j.canlet.2013.05.001. Epub 2013 May 9.

55. Putcha. G.V., Deshmukh, M., Johnson ,E.M. . Inhibition of apoptotic signaling cascades causes loss of trophic factor dependence during neuronal maturation. J Cell Biol. 2000 May 29;149(5):1011-8.

56. Brooks, C., Dong, Z. Regulation of mitochondrial morphological dynamics during apoptosis by Bcl-2 family proteins: a key in Bak? Cell Cycle. 2007 Dec 15;6(24):3043-7. Epub 2007 Oct 2. Review.

57. Vander Heiden, M.G., Chandel, N.S., Williamson, E.K., Schumacker, P.T. Bcl-xL regulates the membrane potential and volume homeostasis of mitochondria. Thompson CB Cell. 1997 Nov 28;91(5):627-37.

58. Can, A., Akev, N., Ozsoy, N., Bolkent, S., Arda, B.P., Yanardag, R., Okyar, A. Effect of Aloe vera leaf gel and pulp extracts on the liver in type-II diabetic rat models. Biol Pharm Bull. 2004 May;27(5):694-8.

59. Beya, W., Davidson, B., Erlwanger, K.H .The effects of crude aqueous and alcohol extracts of Aloe vera on growth and abdominal viscera of suckling rats. 2012 Jul 1;9(4):553-60. eCollection 2012.

60. Lebitsa, T., Viljoen, A., Lu, Z., Hamman, J. In vitro drug permeation enhancement potential of aloe gel materials. Curr Drug Deliv. 2012 May;9(3):297-304.

61. Langmead, L., Makins, R.J., Rampton, D.S. Anti-inflammatory effects of aloe vera gel in human colorectal mucosa in vitro. Aliment Pharmacol Ther. 2004 Mar 1;19(5):521-7. 
62. Eamlamnam, K., Patumraj, S., Visedopas, N., Thong-Ngam, D. Effects of Aloe vera and sucralfate on gastric microcirculatory changes, cytokine levels and gastric ulcer healing in rats. World J Gastroenterol. 2006 Apr 7;12(13):2034-9.

63. Bolkent, S., Akev, N., Ozsoy, N., SengezerInceli, M., Can, A., Alper, O., Yanardag, R. Effect of Aloe vera (L.) Burm. fil. leaf gel and pulp extracts on kidney in type-II diabetic rat models. Indian J Exp Biol. 2004 Jan;42(1):48-52.

64. Boudreau, M.D., Beland, F.A. An evaluation of the biological and toxicological properties of Aloe barbadensis (miller), Aloe vera. J Environ Sci Health C Environ Carcinog Ecotoxicol Rev. 2006 Apr;24(1):103-54.

65. Ozsoy, N., Candoken, E., Akev, N. Implications for degenerative disorders: antioxidative activity, total phenols, flavonoids, ascorbic acid, betacarotene and beta-tocopherol in Aloe vera. xid Med Cell Longev. 2009 Apr-Jun;2(2):99-106.
66. Mahbub, A.A., Le Maitre, C.L., HaywoodSmall, S.L., McDougall, G.J., Cross, N.A., Jordan-Mahy, N. Differential effects of polyphenols on proliferation and apoptosis in human myeloid and lymphoid leukemia cell lines. Anticancer Agents Med Chem. 2013 Dec;13(10):1601-13.

67. Gupta, V.K., Malhotra, S. Pharmacological attribute of Aloe vera: Revalidation through experimental and clinical studies. Ayu. 2012 Apr;33(2):193-6. doi: 10.4103/09748520.105237.

68. Friedman, R.N., Si, K. Initial characterization of the effects of Aloe vera at a crayfish neuromuscular junction. Phytother Res. 1999 Nov;13(7):580-3.

69. Lu, Z.Q., Deng, Y.J., Lu, J.X. Effect of aloe polysaccharide on caspase-3 expression following cerebral ischemia and reperfusion injury in rats. Mol Med Rep. 2012 Aug;6(2):371-4. doi: 10.3892/mmr.2012.927. Epub 2012 May 24. 